\title{
NRC Inspections: Risk-Informed and Performance-Based
}

\author{
Michelle R. Beardsley \\ Division of Nuclear Materials Safety, U.S. Nuclear Regulatory Commission, King of Prussia, Pennsylvania
}

In 2002, the U.S. Nuclear Regulatory Commission (NRC) revised its regulations governing the use of byproduct materials for medical purposes (10 CFR Part 35). These changes were the result of a detailed, 4-year examination of the issues surrounding the medical use program of the NRC and are stated in the latest revision to its medical policy statement, published in the Federal Register on August 3, 2000. As part of an overall program for revising its regulatory framework for medical use, the NRC revised its medical policy statement in keeping with the goal of focusing regulation on those medical procedures that pose the highest risk and structuring the regulations to be risk-informed. NRC inspection procedures were also revised to focus on high-risk activities through a performance-based approach, that is, through observations and interviews with licensee personnel performing NRC-regulated tasks. The purpose of this article is to inform the radiation worker (nuclear medicine technologist or authorized user physician) of the revised focus of the medical use program of the NRC and inspection procedures relative to nuclear medicinelicensed activities. After reading this article, the radiation worker should be able to describe the concept of risk-informed, performance-based regulations and inspections, identify areas of highrisk activities in the nuclear medicine laboratory, and describe techniques used by the NRC inspector to determine the licensee's compliance with the regulations.

Key Words: NRC inspections; risk-informed; performancebased

J Nucl Med Technol 2008; 36:129-131

DOI: 10.2967/jnmt.107.049429

$\mathbf{I}$ nspections by the U.S. Nuclear Regulatory Commission (NRC) have been refocused toward the risk-informed, performance-based revisions made to the medical use regulatory framework. For example, before these revisions, an inspection would usually consist of the inspector performing a painstaking review of every entry in the licensee's numerous binders of required records. More often

\footnotetext{
Received Nov. 27, 2007; revision accepted Feb. 18, 2008.

For correspondence or reprints contact: Michelle R. Beardsley, Division of Nuclear Materials Safety, U.S. Nuclear Regulatory Commission, Region I, 475 Allendale Rd., King of Prussia, PA 19406.

E-mail: mrb@nrc.gov

*NOTE: FOR CE CREDIT, YOU CAN ACCESS THIS ACTIVITY THROUGH THE SNM WEB SITE (http://www.snm.org/ce_online) THROUGH SEPTEMBER 2010.

COPYRIGHT @ 2008 by the Society of Nuclear Medicine, Inc.
}

than not, the inspector would find at least one instance of an incomplete or missing record, which would result in a minor violation that did not affect radiation safety. The emphasis of the inspection appeared to be on records completion, which did not necessarily reflect the quality of the radiation safety program as a whole. Now that the focus of the NRC has been directed toward regulating and inspecting those areas in which exposure to personnel, patients, and members of the public pose the highest risk, NRC inspectors have broad latitude in determining whether the licensee complies with the regulations. Inspectors determine compliance by observing workers performing regulated tasks and by interviewing staff and do not rely solely on records completion.

\section{BACKGROUND}

As part of its regulatory process, the NRC issues policy statements to inform licensees, other federal and state agencies, and the public of its general intentions in regulating the use of radiation and radioactive materials. In 1979, the NRC published a policy statement, Regulation of the Medical Uses of Radioisotopes (44 FR 8242, February 9, 1979) (1). The statement outlined the intention of the NRC to continue to regulate the medical use of radioisotopes as necessary to provide for the radiation safety of workers and the general public; regulate the radiation safety of patients where justified by the risk to patients and where voluntary standards, or compliance with these standards, were inadequate; and minimize the intrusion of the NRC into medical judgments affecting patients and into other areas traditionally considered to be a part of the practice of medicine (1). After extensive reviews of the medical use program by both the NRC and the National Academy of Sciences' Institute of Medicine, the NRC published a document in the Federal Register on August 6, 1997 (62 FR 42219-42220) entitled Medical Use of Byproduct Material: Issues and Request for Public Input (2). After a period for public review and comments, the final medical use policy statement was published on August 3, 2000 (65 FR 47654). This policy statement revises the one published in 1979 and informs NRC licensees, other federal and state agencies, and the public of the general intentions of the NRC regarding the regulation of the medical use of byproduct material. The final medical use policy statement specifies that the NRC will continue to regulate the uses of radionuclides in medicine as 
necessary to provide for the radiation safety of workers and the general public; the NRC will not intrude into medical judgments affecting patients, except as necessary to provide for the radiation safety of workers and the general public; when justified by the risk to patients, the NRC will regulate the radiation safety of patients primarily to ensure that the use of radionuclides is in accordance with the directive of the physician; and in developing a specific regulatory approach, the NRC will consider industry and professional standards that define acceptable approaches of achieving radiation safety (3). The policy published in 1997 was different from the policy that was in place until 1979 in that it specified that patient safety would be regulated primarily to ensure that the use of radionuclides was in accordance with the directive of the physician and that industry and professional standards would be considered in the regulatory process. The revisions to this policy statement are one component of the overall program of the NRC for revising its regulatory framework to focus on those medical procedures that pose the highest risk and also to structure its regulations and inspections to be more risk-informed and performance-based (1). Consequently, the NRC revised 10 CFR Part 35, which governs the medical use of byproduct material, in 2002 on the basis of the revised policy statement (4). Some key attributes of the revised Part 35 include changes to the training and experience requirements for authorized users; changes to the requirements for those activities or materials with low-risk significance (i.e., $35.100,35.200)$, such as instrument calibrations (35.60, 35.61 , and 35.63), area surveys (35.70), and radiation safety committee requirements (35.24 [f]); and additional requirements for those procedures with high-risk significance (i.e., $35.300,35.400,35.600$, and 35.1000) and that require a written directive (35.40 and 35.41).

\section{APPLICABILITY}

The results of a study commissioned by the NRC to identify risk-informed regulatory options for byproduct material systems was published in Risk Analysis and Evaluation of Regulatory Options for Nuclear Byproduct Material Systems (5). This study identified existing and potential physical and procedural barriers that limited dose to workers and the public and analyzed each system under normal and abnormal (accident) conditions. It defined risk as a "compilation of possible system states and the associated frequencies and consequences." For each system, the study examined the frequency with which a task was performed that resulted in whole-body radiation exposure. The study considered the following 4 physical conditions or safety functions that should be controlled to limit the consequences of using a given radionuclide, given its inherent toxicity: source strength, shielding, confinement, and access (5).

Volume 2 of Risk Analysis and Evaluation of Regulatory Options for Nuclear Byproduct Material Systems studied medical systems-including generator elution, generator preparation, and diagnostic and therapeutic nuclear medicine systems. For these types of systems, the main hazards were attributed to the $\beta$-particles and $\gamma$-rays produced by the radioisotopes typically used and administered to patients, including ${ }^{99 \mathrm{~m}} \mathrm{Tc},{ }^{131} \mathrm{I},{ }^{133} \mathrm{Xe},{ }^{32} \mathrm{P}$, and ${ }^{89} \mathrm{Sr}$. For nuclear medicine diagnostic studies and therapeutic procedures, the study identified the main receivers of exposure to be individuals involved in the receipt, preparation, and administration of the dosages (nuclear medicine technologist, supervised individual, or authorized user physician). Consequently, the study postulated that these individuals' exposures could be reduced through administrative controls, procedures, and training. For members of the public, the role of the regulations is to limit exposure by controlling access to radioactive materials and radiation areas. Risk analysis performed for therapeutic procedures using ${ }^{131} \mathrm{I}$ (liquid and solid capsules), ${ }^{89} \mathrm{Sr}$, and ${ }^{32} \mathrm{P}$ showed that the risk associated with normal operations for both the public and the worker was greater than that associated with accidents. The major contributor of exposure to the worker during normal operations was from patients who received large therapeutic dosages of ${ }^{131} \mathrm{I}$ and were admitted to the hospital for several days. For the public, the major contributor to risk was from exposure to the family members of patients who were administered these dosages and released in accordance with 10 CFR Part 35.75. The study found that the risk attributed to accidental exposure of the worker (e.g., during cleanup of the patient's emesis or urine after administration of ${ }^{131} \mathrm{I}$ ) was about half that from normal operations. However, the study cautioned about comparing the risk from normal events with the risk from accidents, in view of the relative abundance of data on normal events versus the scarcity of data on accidents. The total risk to the public because of accidents is small. This risk would be from a family member being near the radioactive material $\left({ }^{131} \mathrm{I}\right)$ during dosage administration. This practice is not allowed by most facilities, however, except in cases involving a patient who is a minor ( 6 ).

This report also included risks associated with other tasks such as disposal and patient release; however, the exposure encountered during normal operations and accidents was considered small, compared with the exposure associated with these other tasks.

\section{RISK-INFORMED, PERFORMANCE-BASED INSPECTIONS}

NRC inspection manual chapter 2800 establishes the inspection program for licensees authorized to possess, use, transfer, and dispose of radioactive material associated with various types of use. It outlines certain areas on which an inspector should focus to develop conclusions about a licensee's performance. These areas include security or control of licensed material, shielding of licensed material, comprehensive safety measures, radiation dosimetry programs, radiation instrumentation and surveys, radiation safety training and practices, and management oversight. The areas are risk-informed in that experience has shown them to be of relatively higher risk. Chapter 2800 instructs 
the inspector to use a performance-based approach to evaluate the areas of focus. A performance-based approach encourages the inspector to rely on direct observance of work (instead of relying solely on examination of a licensee's documents), interviews with licensee workers, demonstrations by cognizant workers performing NRC-regulated tasks, independent measurements of radiologic conditions at the licensee's facility by the inspector, and, where appropriate, a review of select records. If an inspector concludes that the licensee's performance is satisfactory from a general review of select aspects of an area of focus, the inspection of that area is considered complete (7).

As noted previously, the main individuals who are exposed to radiation in nuclear medicine activities are the nuclear medicine technologist, supervised individual, or authorized user physician who receives, prepares, and administers radiopharmaceutical diagnostic and therapeutic dosages. A performance-based inspection of these activities may include the inspector's observing and interviewing the worker performing or demonstrating the procedure for generator elution or radiopharmaceutical dosage preparation and administration. These observations and interviews can assist the inspector in determining the adequacy of the worker's training and knowledge of the radiation safety program. The inspector will observe the use of administrative and physical controls (syringe shields, L-blocks, laboratory coat, and gloves) and procedures (generator elution, surveys, dosimetry, and written directive). Select records, such as written directives, bioassays, and personnel dosimetry, may also be reviewed for verification. In addition, the inspector may observe the worker performing real or mock demonstrations of survey-meter operability checks or instrument calibrations and performing various surveys of rooms, hands, and packages containing radioactive materials. A part of the inspection may include interviews with physicians, nurses, and ancillary personnel who may be involved with the care of patients who have been administered therapeutic dosages and admitted to the hospital to assess whether exposure is being kept within the limits specified in 10 CFR Part 20. Additionally, records of personnel bioassays and patient, area, and room surveys may be examined, and independent surveys may be performed by the inspector for verification. The inspector may review the minutes of select radiation safety committee meetings, including a review of the licensee's ability to identify and respond to areas of noncompliance with NRC regulations to assess management oversight of the radiation safety program.

In all cases, inspectors are required to assess whether licensed materials are being kept secure through direct observation (i.e., through security guards), through physical and personnel barriers (e.g., locked doors or keycard access), or through both means.

\section{CONCLUSION}

As part of the overall program for updating its regulatory framework for medical use, the NRC has revised its medical policy statement, including the regulations that govern the medical use of byproduct material. The goals of this program are to focus the regulations on those medical procedures and tasks that pose the highest risk of wholebody exposure and to structure the regulations to be more risk-informed and performance-based. NRC inspection procedures have been revised accordingly, and NRC inspectors are directed to focus their efforts on those activities, tasks, and procedures that may involve the risk of overexposure from licensed activities to patients, workers, and members of the general public. Inspection guidance focuses the inspector on determining whether the licensee's program complies with NRC regulations through direct observance of work, interviews with cognizant workers, demonstrations of workers performing NRC-regulated tasks or procedures, independent measurements, and, where appropriate, a review of select records. The NRC expects that by focusing its regulations and inspections in a riskinformed manner, licensees will take measures to prevent overexposure, medical events, or the release, loss, or unauthorized use of radioactive material.

\section{ACKNOWLEDGMENTS}

I thank the following individuals for their technical review and support: Pamela J. Henderson, chief, Division of Nuclear Materials Safety Medical Branch, USNRC, Region I; Brian E. Holian, director, Division of Nuclear Materials Safety, USNRC, Region I; and Sunil Weerakkody, acting deputy director, Division of Nuclear Materials Safety, USNRC, Region I.

\section{REFERENCES}

1. Federal Register 8242, February 9, 1979 (Volume 44). USNRC, Rules and Regulations, Title 10, Chapter 1, CFR-Energy, Commission Notices, Policy Statements, Regulation of the Medical Use of Radioisotopes.

2. Federal Register 42219-42220, August 6, 1997 (Volume 62). USNRC, Rules and Regulations, Title 10, Chapter 1, CFR-Energy, Commission Notices, Policy Statements, Medical Use of Byproduct Material: Issues and Request for Public Input.

3. Federal Register 47654, August 3, 2000 (Volume 65). USNRC, Rules and Regulations, Title 10, Chapter 1, CFR-Energy, Commission Notices, Policy Statements, Medical Uses.

4. Code of Federal Regulations Title 10, Parts 20, 35. Energy. 2006.

5. Schmidt ER, Youngblood RW, Meyer JF, et al. Risk analysis and evaluation of regulatory options for nuclear byproduct material systems. USNRC NUREG/ CR-6642. 2000; Vol. 1:2-(8-12).

6. Schmidt ER, Youngblood RW, Meyer JF, et al. Risk analysis and evaluation of regulatory options for nuclear byproduct material systems. USNRC NUREG/ CR-6642. 2000; Vol. 2:3-(52-103).

7. U.S. NRC. Inspection manual. Manual chapter 2800, materials inspection program, inspection procedures 87130 and 87131 . Available at: http://www.nrc. gov/reading-rm/doc-collections/insp-manual/manual-chapter/mc2800.pdf. Accessed July 16, 2008. 